\title{
Potential in vitro elicitation of secondary metabolite using sodium azide in tissue culture of Nigella sativa and its effect on DNA damage inhibition
}

Mohammed Shariq Iqbal ${ }^{1}, Z_{\text {Zahra Iqbal }}^{2}$, Abeer Hashem ${ }^{3,4}$, Elsayed Fathi Abd_Allah ${ }^{5}$, Asif Jafri $^{6}$, Mohammad Israil Ansari*7

${ }^{1}$ Amity Institute of Biotechnology, Amity University Uttar Pradesh, Lucknow campus, Lucknow-226 028, India

${ }^{2}$ Department of Biochemistry, Faculty of Science, Chulalongkorn University, Bangkok 10330, Thailand

${ }^{3}$ Botany and Microbiology Department, College of Science, King Saud University, P.O. Box. 2460, Riyadh 11451, Saudi Arabia

${ }^{4}$ Mycology and Plant Disease Survey Department, Plant Pathology Research Institute, Agriculture Research Center, Giza, Egypt.

${ }^{5}$ Plant Production Department, College of Food and Agricultural Sciences, King Saud University, P.O. Box. 2460, Riyadh 11451, Saudi Arabia

${ }^{6}$ Molecular Endocrinology Lab, Department of Zoology, University of Lucknow, Lucknow- 226007 , India

${ }^{7}$ Department of Botany, University of Lucknow, Lucknow-226 007, India

*Corresponding author: Department of Botany, University of Lucknow, Lucknow-226 007 , India. Tel.: +91-9839541698. Email: ansari_mi@lkouniv.ac.in, ansari_mi@hotmail.com

\begin{abstract}
Nigella sativa (NS) is an effective medicinal plant possessing noteworthy antioxidant property. In NS, there are more than hundred phyto-chemicals reported, out of which thymoquinone is the utmost active phyto-constituent having sturdy antioxidative property. Thymoquinone is a cyclicdione, when reacts with sodium azide, converts into $\alpha$-azido ketones i.e its analogs which
\end{abstract}


are handy with extensive range of reactions. Sodium azide induces stress in plants thereby, modulating the antioxidant system. The present investigation was planned to elucidate the effect of sodium azide at different concentrations $(5 \mu \mathrm{M}, 10 \mu \mathrm{M}, 20 \mu \mathrm{M}, 50 \mu \mathrm{M}, 100 \mu \mathrm{M}$ and $200 \mu \mathrm{M})$ on its secondary metabolites (mainly thymoquinone) in NS callus culture extract (NSE). The results showed sodium azide effect on thymoquinone content and a concentration dependent boost in antioxidant property. It was also observed that thymoquinone content and percent yield (analyzed by RP-HPLC; Reverse Phase- High Performance Liquid Chromatography) were minimum $(0.033 \pm 0.006 \%$ and $0.420 \pm 0.045 \%$, respectively) at $200 \mu \mathrm{M}$ sodium azide used. Whereas, antioxidant activity (analyzed by DPPH; 2, 2-diphenyl-1-picrylhydrazyl) was found to be maximum $(3.873 \pm 0.402 \%)$ at same dose. Further, analysis was done for inhibition of oxidative DNA damage at different concentrations of sodium azide on NSE, maximum inhibition of DNA damage $(0.243 \pm 0.017 \%)$ was found at $200 \mu \mathrm{M}$ concentration of sodium azide. When correlated, strong positive correlation was observed between percent yield and percent thymoquinone, antioxidant property and inhibition of DNA damage. Whereas, strong negative correlation was observed between percent yield and antioxidant property, percent thymoquinone and antioxidant property, percent thymoquinone and inhibition of DNA damage. The findings evidently point out that the content of thymoquinone, antioxidant property and inhibition of DNA damage was affected by sodium azide.

Keywords: Antioxidant, Nigella sativa, secondary metabolites, thymoquinone, DNA damage 


\section{Introduction}

Nigella sativa (NS) belonging to the family Ranunculaceae, generally known as black cumin or black seed and usually grown in south Asian regions mainly India, Pakistan and Srilanka [1]. Various studies on medicinal properties of NS showed its promising effects such as anti-cancer, anti-inflammatory, anti-parasitic, anti-analgesic, anti-microbial, anti-stress, antioxidant and antiasthmatic [2-4]. A recent study showed its protective effect against diazinon cardio toxicity in rat model [5]. These activities are mainly due to the presence of active phytochemicals present in it [6]. Phytochemicals are the secondary metabolites and have been used for wide applications as an herbal medicine, dietary regimens, fragrance industry, flavoring industry, and for preservation purposes [7-9]. Secondary metabolites possess vast applications, mainly due to their antioxidative potential and various other biological abilities. NS seed oil composed of various secondary metabolites viz. p-cymene monoterpenes, $\beta$-pinene, $\alpha$-thujene, $\gamma$-terpinene, $\alpha$-pinene, nigellone, caracole, thymoquinone and thymol [10]. Thymoquinone is one of the most abundant and firstly isolated phytochemical of NS [11]. Thereby, numerous studies based on pharmacological importance of thymoquinone have been reported $[12,13]$. Various studies reported that of NS anticarcinogenic activity was due to its main secondary metabolite, thymoquinone. An investigation exposed the cytotoxic effect of thymoquinone on keratinocyte cells [14]. Moreover, an anti-tumor and antiproliferative activity, thymoquinone was also reported in prevention of tumors progressions via angiogenesis and metastasis [15]. Studies reported that thymoquinone can destroy cancerous cells by the specific targeted mechanisms, which is unlike to traditional treatments like radio or chemo therapy $[16,17]$. Several in vivo and in vitro studies on thymoquinone antitumor activity has revealed significant apoptotic effects [18], however thymoquinone's deprived effectiveness [19] and meagre bio-availability [20] is the crucial disadvantage as a substantial curative secondary metabolite. Another foremost difficulty, that confines usage of thymoquinone as a therapeutic biomolecule, is its slighter water solubility and cytotoxic effects at higher dosage. Furthermore, studies reported that thymoquinone on reaction with sodium azide converted into its structural analogs $[21,22]$. The produced analogs may possess antioxidant activity and can be a good source of antioxidants [23]. Therefore, in order to elicit secondary metabolites, in vitro technique like plant tissue culture is used to obtain it in amplified quantities and in a judicious time. Several plant tissue culture methods have been comprehensively investigated in order to increase the fabrication of plant secondary metabolites [24]. In order to increase the production of desired 
secondary metabolites in plant tissue culture, elicitation technique is commonly used by numerous biotic or abiotic factors. Elicitors in callus cultures are generally known as signaling molecules because they interact with signal transduction cascade, resulting in expression of related gene with the synthesis of secondary metabolites [25]. With consideration to these earlier reports on thymoquinone, for its therapeutic applications, the present investigation was performed to produce structural analogs of thymoquinone using micropropagation technique by treating NS callus culture with sodium azide that might produce more potent antioxidants. Although, it may also create stress conditions and stimulate other antioxidants for hyper production. Interestingly, in both the situations, antioxidant ability of the plant might enhance and can be advantageous for pharmaceutical and nutraceutical formulations.

\section{Result and Discussion}

The seeds of NS were germinated on Murashige and Skoog (MS) medium for the callus proliferation, supplemented with 2,4-D (2,4-Dichlorophenoxyacetic acid) and thereafter, calli obtained were transferred on MS medium with sodium azide as an elicitor (Figure 1).
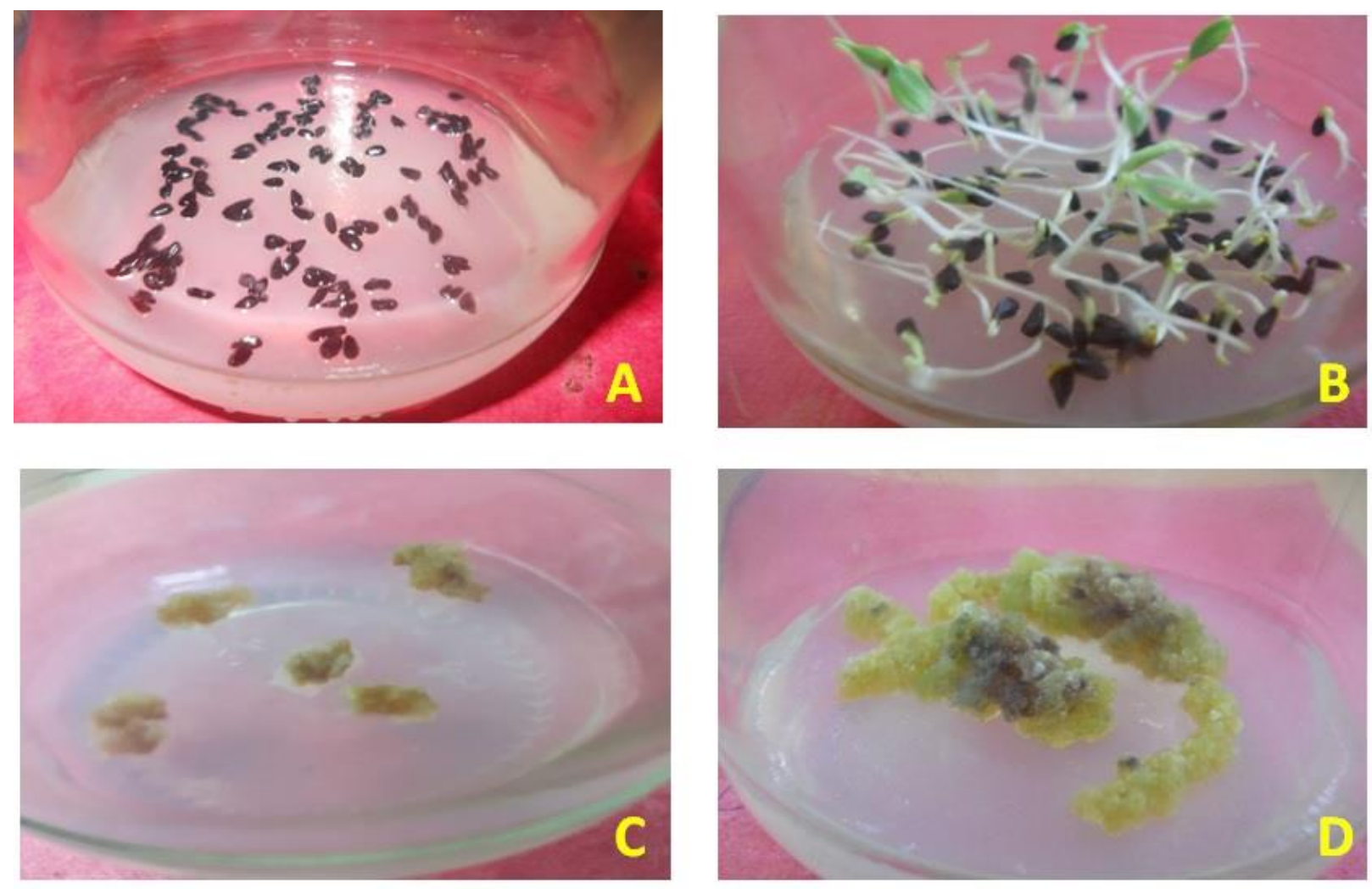
Figure 1. NS seed germination on MS medium supplemented with 2,4-D for callus formation and further elicitation with sodium azide. (A) NS seeds on MS media; (B) NS seedlings; (C) Callus of NS in MS media supplemented 2,4-D; (D) Sodium azide treatment on NS Callus.

Sodium azide encourages stress condition in callus of NS and results into excess or deprived production of secondary metabolites. In addition to this, sodium azide induces biochemical alterations that enhanced the antioxidant activity. Thymoquinone was extensively studied secondary metabolite of NS and when it interact with sodium azide converted into its analogs $[21,26]$, might be of therapeutic importance. Furthermore, sodium azide may cause stress condition and enhances the production of secondary metabolites in NS callus culture extract (NSE). The present study showed the effect of sodium azide on different parameters with respect to its antioxidant activity on NSE. Initially, sodium azide effect on percent yield of extracts was observed, maximum extract yield $(0.860 \pm 0.065 \%)$ was obtained at $0 \mu \mathrm{M}$ (control), while, minimum extract yield $(0.453 \pm 0.037 \%)$ was found at $100 \mu \mathrm{M}$ sodium azide treatment in NSE. When further increased concentration of sodium azide was used i.e at $200 \mu \mathrm{M}$, no significant effect was observed (Figure $2 \mathrm{~A}$ ). The results were in agreement with the previous report of Yafizham and Bagus [27], where sodium azide at 0-1.60 mM concentrations were used on Capsicum annum L. seeds, affecting the various morphological and physiological parameters and resulted in decreased biomass availability. It was also reported in a study on NS, where increasing concentrations of sodium azide treatment affected the extract yield, whereas, higher concentration of sodium azide does not affected the extract yield [23]. It was observed from the findings that sodium azide virtuously affect the percent yield of extract. Interestingly, it was also reported that percent yield of the extract is related to the chemical constituent of the plant $[28,29]$. These findings indicate that sodium azide interacts with phytochemicals of the plant, and thereby altering the bioavailability of secondary metabolites and therefore, affecting the yield of extract. Thus, it can be concluded that percent yield is an imperative feature for phytochemical extracts with respect to its primary and secondary metabolites composition. 


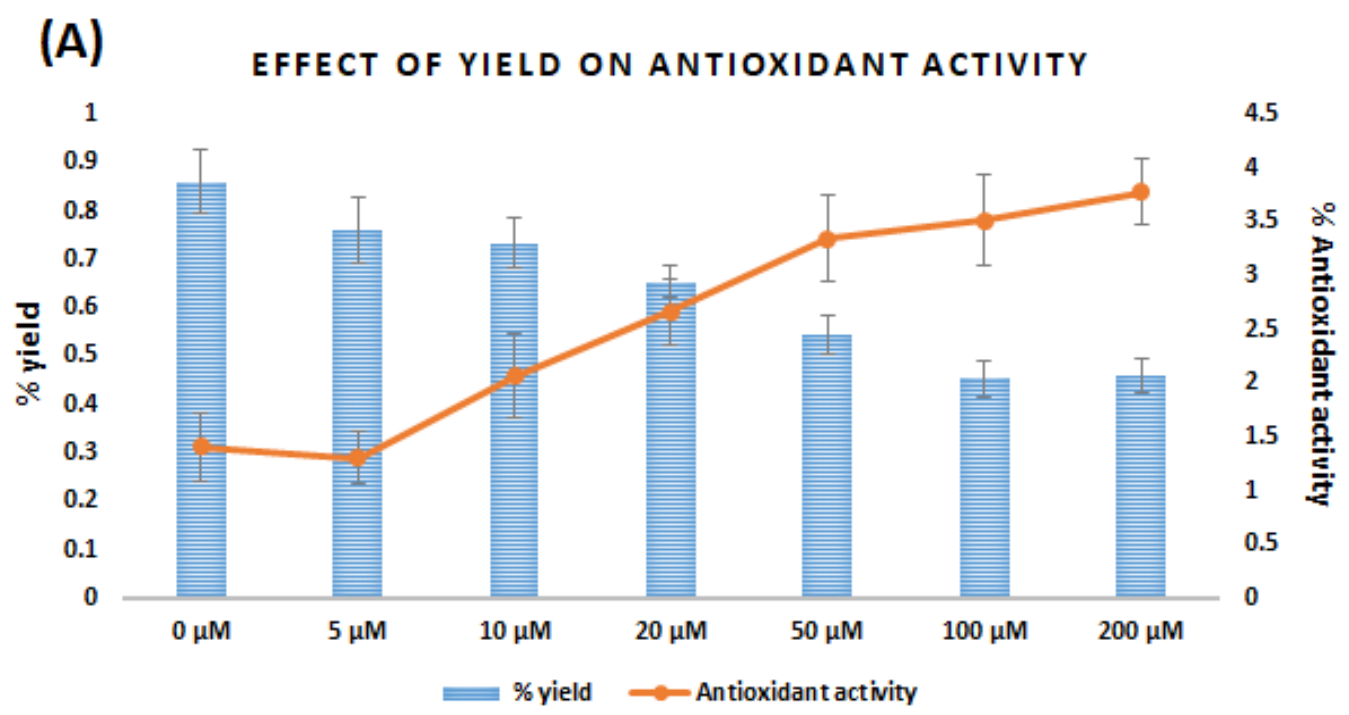

(B) EFFECT OF THYMOQUINONE CONTENT ON ANTIOXIDANT

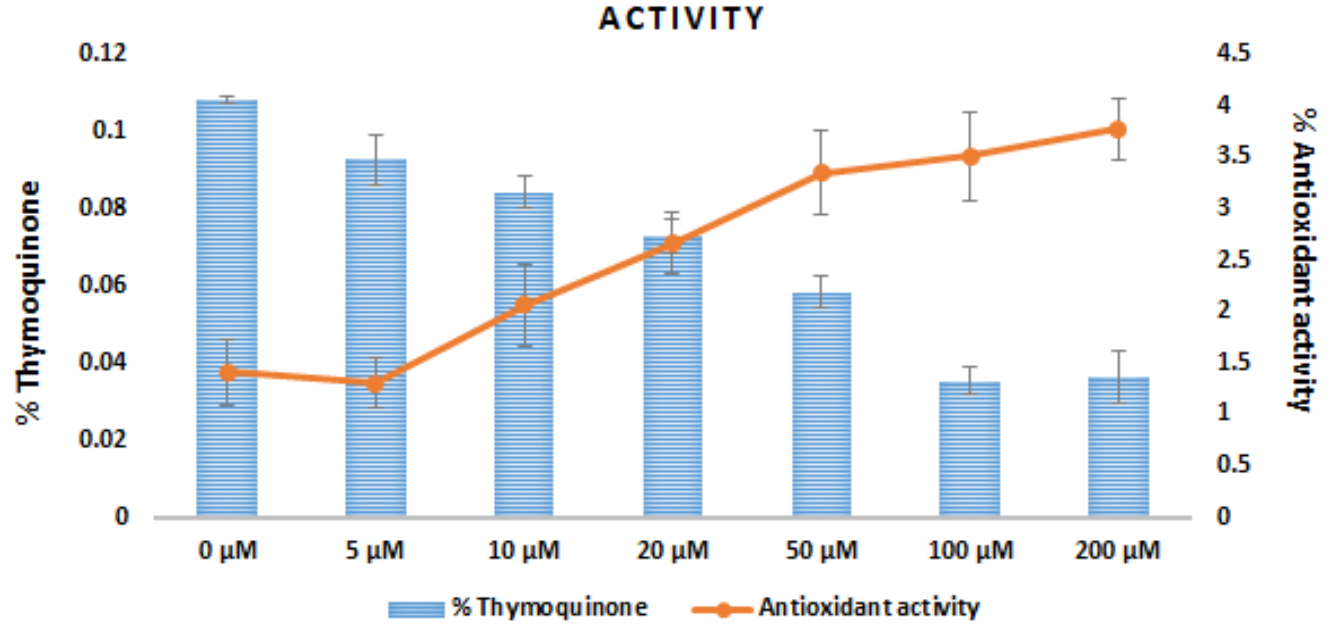

(C) EFFECT OF THYMOQUINONE CONTENT ON DNA DAMAGE

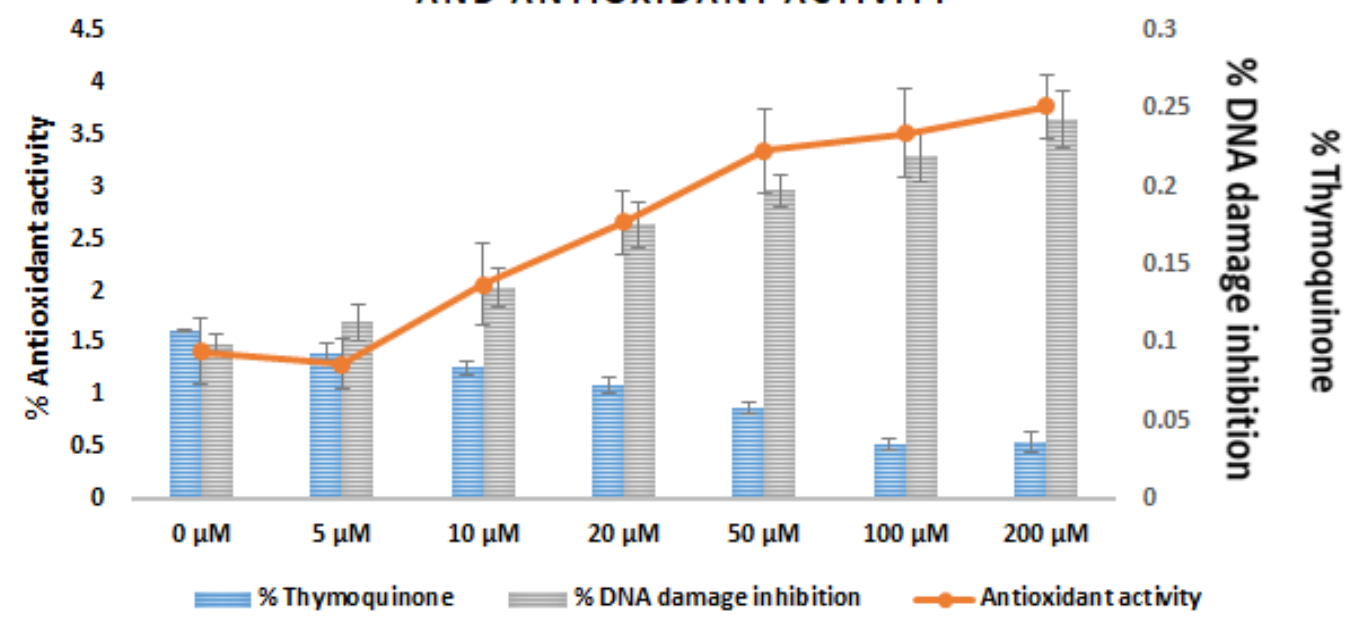


Figure 2. (A) Antioxidant activity of NS callus culture extract (NSE) (after sodium azide treatment), with respect to percent yield. (B) Antioxidant activity with respect to percent thymoquinone content, and (C) Antioxidant activity with respect to percent thymoquinone content and percent DNA damage inhibition. The data are represented as mean \pm SD.

With consideration to NS phytochemical analysis the percent thymoquinone composition was evaluated using RP-HPLC (Reverse Phase- High Performance Liquid Chromatography). The spectrum scanning of standard thymoquinone was also done in order to determine the absorbance of thymoquinine using UV-VIS spectrophotometer. It was found that maximum absorbance was detected to be $254 \mathrm{~nm}$. The results are in agreement with our previous findings of Iqbal et al [23]. The present results are also in virtuous agreement with the previous finding of Belete and Dagne, [30], where thymoquinone was analyzed using UV-Visible, HPTLC and NMR techniques with maximum absorbance at 254nm. Further, RP-HPLC analysis of thymoquinone showed maximum percent of thymoquinone $(0.108 \pm 0.0007 \%)$, in the NSE treated with $0 \mu \mathrm{M}$ concentration of sodium azide while, minimum percent of thymoquinone $(0.035 \pm 0.003 \%)$ was observed at $100 \mu \mathrm{M}$ sodium azide treated NSE. It was noteworthy that higher concentration of sodium azide at $200 \mu \mathrm{M}$, no effect was observed (Figure 2 B). When correlation was made, a strong positive correlation (0.9953) was observed between percent thymoquinone composition and percent yield of NSE (Figure 3 A). Furthermore, consideration to correlation analysis, it can be assumed that sodium azide possess a robust effect on secondary metabolites (mainly thymoquinone) as well as other metabolites on callus culture of NS The dwindling content of thymoquinone with consideration to percent yield of the NSE indicates modifications in its structure. It's a strong possibility of formation of analogs of thymoquinone when reacted with sodium azide treated NS callus culture extract. It was reported by Moore and Shelden [21] and again by Faiz et al, [26] that sodium azide interacts with thymoquinone to form 3-amino-G-azido-2-methyl-5-isopropyl-1,4-benzoquinone. Thus, the alterations in conformational structure of thymoquinone, an outcome in formation of its analogues compounds. Fieser and Hartwell [31] reported that 2-azido-1,4-napthoquinone when treated with azide ion and 2-chloroquinone forms azidoquinone. In the given reaction the halogen ions are replaced by azide ions in a nucleophilic displacement reaction thereby yielding azidoquinones with an elevation of more than $85 \%$ with purity. With respect to these findings, the present study was 
hypothesized, although this cannot be entirely pondered as a yardstick for the production of thymoquinone analogs, as many additional aspects plays a substantial role in the production of secondary metabolites using plant tissue culture technique.

With respect to the results obtained by RP-HPLC analysis of most active phytochemical, thymoquinone in NS, antioxidant property of the extracts were analyzed to elucidate the effect of sodium azide on secondary metabolites. The antioxidant activity was measured using DPPH (2,2diphenyl-1-picrylhydrazyl) assay, and maximum antioxidant activity (3.773 $\pm 0.302 \%)$ was found at $200 \mu \mathrm{M}$ sodium azide treated NSE, while, minimum $(1.299 \pm 0.242 \%)$ at $5 \mu \mathrm{M}$ concentration of sodium azide (Figure $2 \mathrm{~A}$ ). With respect to the preceding results, correlation analysis was performed in order to elucidate the effect of sodium azide on percent yield, percent thymoquinone content and their effect on antioxidant activity. The analysis showed strong negative correlation (0.9635) between percent yield and antioxidant activity, and between percent thymoquinone content and antioxidant activity (-0.9578). The graphical representation is shown in Figure 3 B, C. The findings indicate that sodium azide interacts with phytochemicals of NS, thereby, enhancing the antioxidant activity, as well as depriving thymoquinone content and percent yield. It could be the possibility that sodium azide has interacted with thymoquinone and converted into its analogs, which are more potent antioxidants. A previous report suggested that sodium azide treatment affects antioxidants levels in NS, either by eliciting the level of secondary metabolites or by inducing conformational changes in its active phyto-constituents (mainly thymoquinone), thus elevating the antioxidant activity [23]. The antioxidant activity of thymoquinone is well known, however its structural analogs are yet to be explored, for more potent antioxidants.

The NSE after treated with sodium azide affected the percent phytochemical constituents and antioxidant activity. Further, with consideration to antioxidant activity, NSE after treated with various doses of sodium azide and standard thymoquinone was analyzed for DNA damage inhibition activity on calf thymus DNA. It was observed from the result that maximum inhibition in DNA damage $(0.243 \pm 0.017 \%)$ was observed at $200 \mu \mathrm{M}$ sodium azide, while, minimum inhibition $(0.099 \pm 0.0006 \%)$ was observed at $0 \mu \mathrm{M}$ of sodium azide treated NSE (Figure $2 \mathrm{C}$ ). Correlation analysis was also performed in order to elucidate the effect of sodium azide on percent yield, percent thymoquinone and its antioxidant activity, thereby having an impact on DNA damage inhibition. A strong positive correlation (0.9881) was observed between DNA damage 
inhibition and antioxidant activity, whereas, strong negative correlation (-0.9812) was observed between thymoquinone percent composition and DNA damage inhibition (Figure 3 D, E). The results were also visualized by agarose gel electrophoresis, and maximum degraded DNA was observed in the lane no. 9 (control i.e calf thymus DNA) with thymoquinone, while, intensity of DNA bands increases with the increase of sodium azide treatment in NSE (Figure 4). It was observed maximum degradation of calf thymus DNA (Figure 4; lane 2) of NSE with $200 \mu \mathrm{M}$ treatment of sodium azide, while minimum degradation is observed (Figure 4; lane 8) of NSE with $0 \mu \mathrm{M}$ treatment of sodium azide (control). It clearly indicates the effect of thymoquinone in DNA degradation. The oxidative mixture degrades the DNA by producing free radicals and as a counterpart, probably, the NSE were scavenging these free radicals, and thus inhibiting the DNA damage. The results clearly showed the inhibition of oxidative damage in a concentration dependent manner. As the concentration of percent yield and percent thymoquinone is decreasing, inhibition of DNA damage is increasing (Figure 4). It clearly indicates that thymoquinone plays a significant role in DNA damage. The findings are in accordance with the earlier report of Gurung et al [32] where DNA damage was reported in human glioblastoma cells by thymoquinone in a dose dependent manner. However, it was also reported that thymoquinone protects DNA damage at low concentrations of $1-10 \mu \mathrm{g} / \mathrm{ml}$ [33]. Interestingly, present study showed that higher concentration of thymoquinone couldn't help in inhibition of DNA degradation, as the free radicals produced by reaction mixture were not completely scavenged by thymoquinone. While, on the other hand NSE after treatment with increased doses of sodium azide showed significant antioxidative effect in DNA damage. The findings are similar to the report of Parray et al [34] where methanolic extract of Crocus sativus showed significant effect on protection of DNA damage. The present study is the initial report representing the in vitro inhibition of DNA damage ability of NS and showing significant effects. These effects may be due to the formation of analogs of thymoquinone, which are more potent antioxidants or due to the elicitation of other secondary metabolites after sodium azide stress condition. Therefore, further more researches are needed to fully elucidate the aforesaid findings. 
(A)

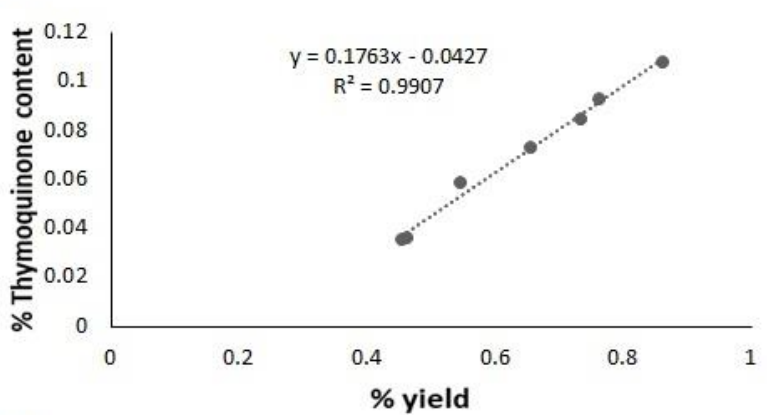

(C)

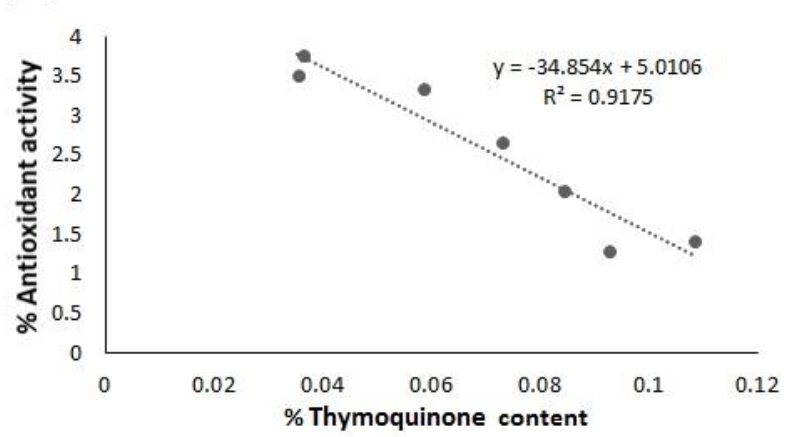

(B)

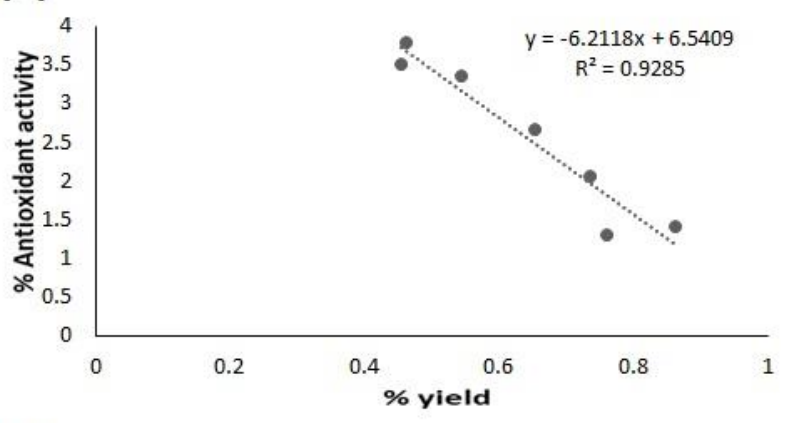

(D)

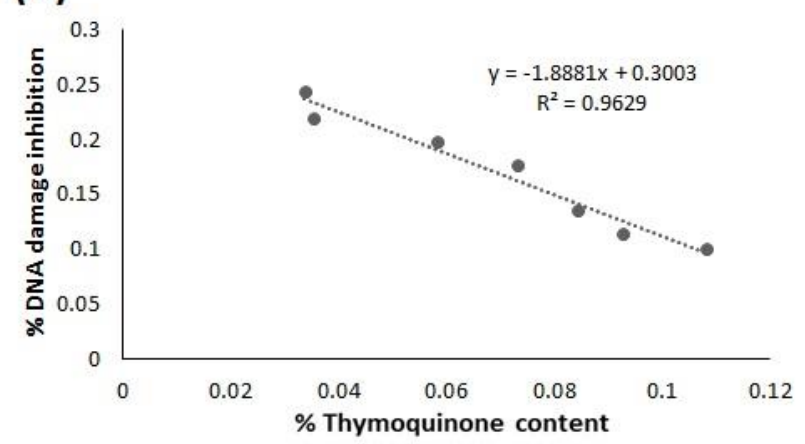

(E)

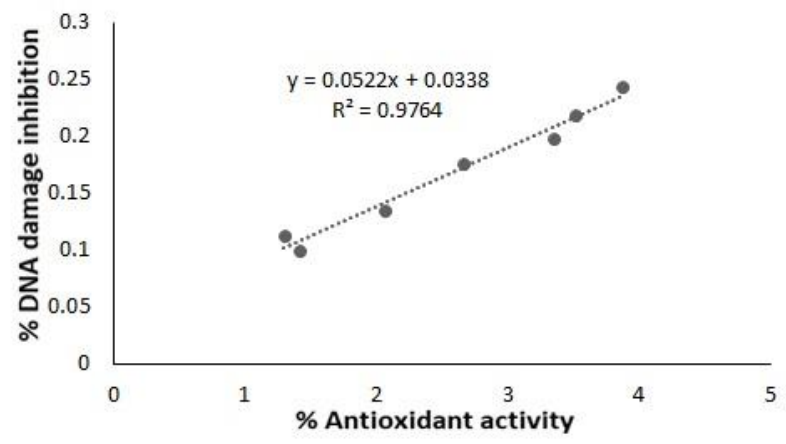

Figure 3. Graphs representing correlation between various parameters studied. Where the graphs showing correlation between (A) \% Thymoquinone content and \% Yield; (B) \% Antioxidant activity and Yield; (C) \% Antioxidant activity and \% Thymoquinone content; (D) \% DNA damage inhibition and \% Thymoquinone content; (E) \% DNA damage inhibition and \% Antioxidant activity 


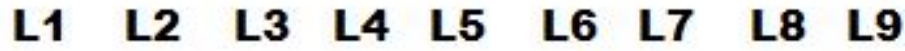

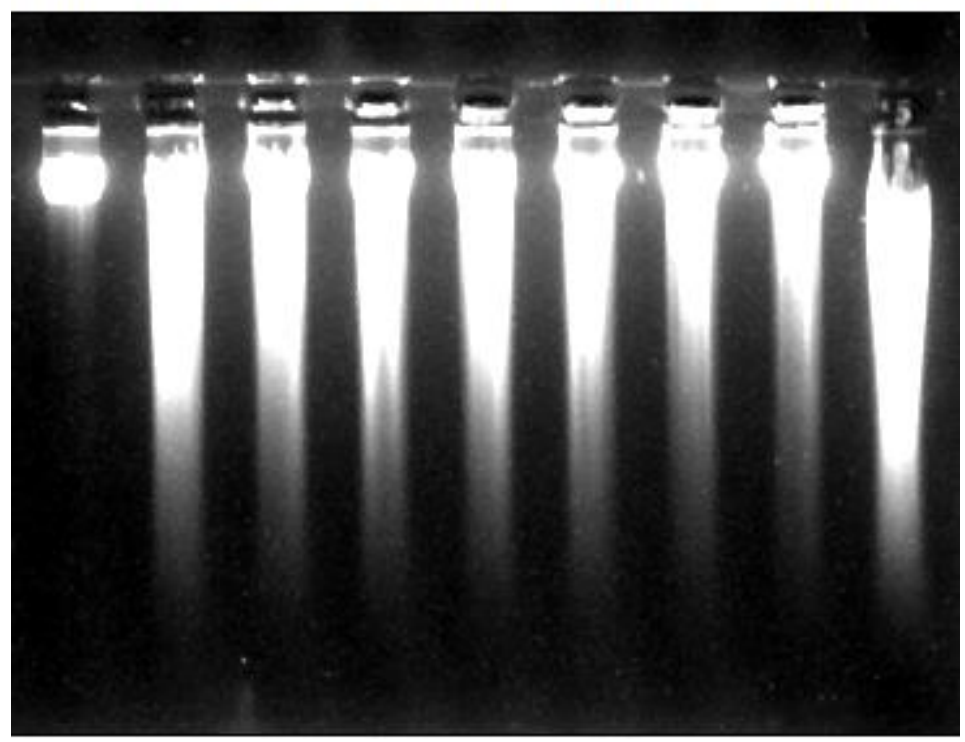

Figure 4. DNA damage inhibition on NSE after treatment with various concentrations of sodium azide. L1: Standard calf thymus DNA; L2, L3, L4, L5, L6, L7, L8 representing calf thymus DNA and NSEs after 200, 100, 50, 20, 10. 5, 0 (Control) $\mu \mathrm{M}$ treatment of sodium azide, respectively; L9 showing calf thymus DNA with 1mM thymoquinone.

\section{Materials and methods}

\subsection{Explant preparation}

The seeds of NS were provided by National Research Centre on Seed Spices (NRCSS), Rajasthan, India for this study. The callus formation and further their extract preparation were done according to the protocol of Iqbal et al [35]. Primarily, soap solution was used to wash the NS seeds for two min and then kept under running tap water for $1 \mathrm{~h}$. To avoid contamination, under laminar air flow seeds were then rinsed with $0.1 \%$ mercuric chloride for $30 \mathrm{sec}$ and then again washed with sterile water for five times. Afterwards, seeds were then rinsed using ethanol (70\%) for $30 \mathrm{sec}$ and again washed with sterile water for five times. The sterile seeds were then transferred onto agar-solidified MS media and then the culture bottles were kept in dark for about six days until germination [36]. After 10 days of germination seedlings were collected on a sterile culture plates. For callus formation, the seedlings were trimmed into $2 \mathrm{~cm}$ length and transferred on agar-solidified MS culture media containing $1 \mathrm{mg} / \mathrm{l}$ concentration of 2, 4- D (2,4-Dichlorophenoxyacetic acid). The 4 weeks old calli were then transferred onto MS culture media supplemented with $0 \mu \mathrm{M}$ (control), 
$5 \mu \mathrm{M}, 10 \mu \mathrm{M}, 20 \mu \mathrm{M}, 50 \mu \mathrm{M}, 100 \mu \mathrm{M}$ and $200 \mu \mathrm{M}$ concentrations of sodium azide. Under cool fluorescent lamps, at 150 lux the culture bottles were kept, with a photoperiod of $16 \mathrm{~h}$ day and $8 \mathrm{~h}$ night at an ambient temperature of $25 \pm 2^{\circ} \mathrm{C}$, to yield healthy calli.

\subsection{Extract preparation}

The $0-200 \mu \mathrm{M}$ sodium azide treated NS calli were used to prepare methanolic extracts $(2.5 \mathrm{~g}$ each NS calli in $10 \mathrm{ml}$ methanol) according to the previous study [37]. The obtained methanolic extracts were analyzed with the help of RP-HPLC. The filtered and dried 1mg of each NSE were dissolved in $1 \mathrm{ml}$ methanol to prepare $1 \mathrm{mg} / \mathrm{ml}$ for stock solution which was then filtered using $0.22 \mu \mathrm{m}$ syringe filter for further studies.

\subsection{Spectrum scanning analysis}

Spectrum scanning analysis was done (Shimadzu UV-1800) for absorbance of thymoquinone in the designed experiments as described using the procedure of Iqbal et al [37].

\subsection{RP-HPLC analysis}

Ultra Fast Liquid Chromatography (UFLC-Shimadzu), was performed for the RP-HPLC investigation [37,38]. Standard pure thymoquinone (99.0\% purity), Sigma-Aldrich, HPLC-grade methanol, Merk, India and Lab Solution Lite software - Shimadzu was used for analysis the data. The mobile phase consisted of methanol: water $(70: 30 \mathrm{v} / \mathrm{v})$, with $1.0 \mathrm{ml} / \mathrm{min}$ flow rate and absorbance at $254 \mathrm{~nm}$, at an ambient temperature of $25-30^{\circ} \mathrm{C}$, the retention time of 7.376 min was obtained. The mobile phase i.e., sample/solvent were filtered through $0.22 \mu \mathrm{m}$ syringe filters and degassed with the help of bath sonicator. Standard thymoquinone stock solution of $1 \mathrm{mg} / \mathrm{ml}$ concentration was prepared in methanol while taking caution for stability (sensitive to light and heat). From 0.0312 to $2.0 \mu \mathrm{g} / \mathrm{ml}$ of concentrations from thymoquinone stock solution was used to plot calibration curve. For the confirmation of peak of thymoquinone and to rebut the trivial deviance in retention time, each extract sample (NSEs) after treatment with doses of sodium azide was introduced together with standard pure thymoquinone solution. Pure thymoquinone standard curve with mean coefficient of determination $\left(\mathrm{R}^{2}\right)=0.99$ and \% RSD was 7.84 was recorded. 


\subsection{DPPH assay for evaluation of antioxidant activity}

For free radical scavenging activity, DPPH method was used to estimate antioxidant activity using the previous protocol of Jafri et al [39]. The reaction mixture comprises of $0.3 \mathrm{ml}$ DPPH $(0.5 \mathrm{mM}$ in ethanol) and $0.5 \mathrm{ml} \mathrm{NSE}$ and final volume was made using ethanol (3.0 ml). Briefly, in $0.5 \mathrm{ml}$ of NSE added $3.0 \mathrm{ml} \mathrm{DPPH}$ and kept the reaction mixture at room temperature for $60 \mathrm{~min}$ and then the absorbance was taken at $517 \mathrm{~nm}$. For blank $3.3 \mathrm{ml}$ of ethanol and $0.5 \mathrm{ml} \mathrm{NSE}$ and for control $3.5 \mathrm{ml}$ ethanol and $0.3 \mathrm{ml} \mathrm{DPPH}$ were used. Using the following formula, the percent antioxidant activity was calculated:

Percent antioxidant activity $=100-($ OD of sample - OD of blank $) \times 100 \div$ OD of control

\subsection{DNA damage inhibition assay}

The antioxidant capacity was investigated by evaluating the DNA damage inhibition assay (in vitro), of the NSE according to the protocol [40]. Calf thymus DNA of $0.025 \%$ was prepared in $20 \mathrm{mM}$ phosphate buffer saline of $\mathrm{pH}$ 7.4. Afterwards, $1 \mathrm{mM}$ thymoquinone and various NSEs were added in Calf thymus DNA solution and then incubated at room temperature for about $15 \mathrm{~min}$. Then, the oxidative substances as mentioned in the protocol were added. The whole reaction mixture was then incubated for $1 \mathrm{~h}$ at $37^{\circ} \mathrm{C}$. The inhibition of DNA damage was quantified by Schimadzu UV- 1800 spectrophotometer at 260nm wavelength. Inhibition of percent DNA damage was calculated using the formula:

Percent Inhibition $=($ Absorbance sample - Absorbance blank $) \div$ Absorbance control $) \times 100$ Furthermore, DNA damage inhibition visualized on agarose gel electrophoresis with the help of Gel Docsystem (DNr Bio imaging system) and photographed.

\subsection{Statistical Analysis}

Results are expressed as mean \pm standard deviation followed by One-way ANOVA using GraphPad Prism software. For statistical data, p-value less than 0.05 were considered as statistically significant. Correlation was assessed between percent antioxidant activity and percent yield, percent antioxidant activity and percent thymoquinone content, percent thymoquinone content and percent yield, percent DNA damage inhibition and percent thymoquinone content using Microsoft excel. 


\section{Conclusion}

The present study demonstrated that due to the treatment of sodium azide in NS callus culture, the extract yield and thymoquinone content decreased, whereas the antioxidant activity increased. The inhibition in DNA damage also seen in a concentration dependent manner may be due to increment in oxidative stress. Correlation analysis also supported the findings where strong positive correlation (0.9953) was observed between thymoquinone percent composition and percent yield of NSE. However, strong negative correlation was observed between percent yield and antioxidant activity (-0.9635); and thymoquinone percent composition and antioxidant activity (-0.9578). Interestingly, a strong positive correlation was observed between inhibition of DNA damage and antioxidant activity (0.9881), while, thymoquinone percent composition and inhibition of DNA damage was negatively correlated (-0.9812). All these observations clearly suggest the effect of sodium azide on NSE, thereby affecting its antioxidant activity, which might be due to the formation of thymoquinone analogs with more potent antioxidant activity or due to the elicitation of other secondary metabolites. Our group is working further on the aforementioned investigation. However, further more studies are recommended to fully elucidate the effect of sodium azide on NSE that would be useful for pharmaceutical and nutraceutical industry.

\section{Acknowledgement}

The authors are thankful to Head Department of Botany, University of Lucknow and Director, Amity Institute of Biotechnology, Lucknow Campus, Lucknow. The authors would like to extend their sincere appreciation to the Researchers Supporting Project Number (RSP-2019/134), King Saud University, Riyadh, Saudi Arabia.

\section{References}

1. Chakraverty, H.L. Plant wealth of Iraqi dictionary of economic plants. Baghdad: 1976, 1, 387-588.

2. Usmani, A.; Mishra, A.; Arshad, M.; Jafri, A. Development and evaluation of doxorubicin self nanoemulsifying drug delivery system with Nigella Sativa oil against human hepatocellular carcinoma. Artificial cells, nanomedicine, and biotechnology. 2019, 47(1), 933-944.

3. Ahmad, A.; Husain, A.; Mujeeb, M.; Khan, S.A.; Najmi, A.K.; Siddique, N.A.; Damanhouri, Z.A.; Anwar, F. A review on therapeutic potential of Nigella sativa: A 
miracle herb. Asian Pac J Trop Biomed. 2013, 3(5), 337-52. doi: 10.1016/S22211691(13)60075-1

4. Burits, M.; Bucar, F. Antioxidant activity of Nigella sativa essential oil. Phytother Res. 2000, 14, 323-328.

5. Danaei, G.H.; Memar, B.; Ataee, R.; Karami, M. Protective effect of thymoquinone, the main component of Nigella Sativa, against diazinon cardio-toxicity in rats. Drug and Chemical Toxicology. 2019, 42 (6), 585-591. doi.org/10.1080/01480545.2018.1454459

6. Ugur, A.R.; Dagi, H.T.; Ozturk, B.; Tekin, G.; Findik, D. Assessment of in vitro Antibacterial Activity and Cytotoxicity Effect of Nigella sativa Oil. Pharmacogn Mag. 2016, 12(4), S471-S474. doi: 10.4103/0973-1296.191459

7. Kalemba, D.; Kunicka A. Antibacterial and antifungal properties of essential oils. Cur Med Chem. 2003, 10, 813-829.

8. Huang, D.; Ou, B.; Prior, R. L. The chemistry behind antioxidant capacity assays. J Agric Food Chem. 2005, 53, 1841-1856.

9. Bano, S.; Jafri, A.; Ahmad, N.; Sharma, A.K.; Arshad, M. A Comparative Antibacterial Activity of Three Common Spices Extract and their Anti-Proliferative and Apoptotic Effectiveness against Human Breast Adenocarcinoma Cells. Pharmacognosy Journal. 2019, 11(1),88-93.

10. Benkaci-Ali, F.; Baaliouamer, A.; Brahim, Y.M.; Chemat, F. Chemical composition of seed essential oils from algerian Nigella sativa extracted by microwave and hydro distillation. Flavour Frag J. 2007, 22, 148-153. doi.org/10.1002/ffj.1773

11. El- Dakhakhny, M. Studies on the chemical constitution of Egyptian Nigella sativa L. seeds. oi1) the essential oil. Planta Medica, 1963, 11, 465-470.

12. Dajani, E.Z.; Shahwan, T.G.; Dajani, N.E. Overview of the preclinical pharmacological properties of Nigella sativa (black seeds): a complementary drug with historical and clinical significance. J. Physiol. Pharmacol. 2016, 67, 801-817.

13. Manju, S.; Malaikozhundan, B.; Withyachumnarnkul, B.; Vaseeharan, B. Essential oils of Nigella sativa protects Artemia from the pathogenic effect of Vibrio parahaemolyticus Dahv2. Journal of Invertebrate Pathology. 2016, doi.org/10.1016/j.jip.2016.03.004 
14. Gali-Muhtasib, H.U.; Kheir, W.G.A.; Kheir, L.A.; Darwiche, N.; Crooks, P.A. Molecular pathway for thymoquinone-induced cell-cycle arrest and apoptosis in neoplastic keratinocytes. Anti-cancer drugs. 2004, 15, 389-399.

15. Peng, L.; Liu, A.; Shen, Y.; Xu, H.-Z.; Yang, S.Z.; Ying, X.Z.; Liao, W.; Liu, H.X.; Lin, Z.Q.; Chen, Q.Y. Antitumor and anti-angiogenesis effects of thymoquinone on osteosarcoma through the NF- $\hat{I}^{\circ} \mathrm{B}$ pathway. Oncology reports. 2013, 29, 571-578.

16. Velho-Pereira, R.; Kumar, A.; Pandey, B.N.; Jagtap, A.G.; Mishra, K.P. Radiosensitization in human breast carcinoma cells by thymoquinone: role of cell cycle and apoptosis. Cell biology international. 2011, 35, 1025-1029.

17. Zhang, L.; Bai, Y.; Yang, Y. Thymoquinone chemosensitizes colon cancer cells through inhibition of NFKB. Oncology letters. 2016, 12, 2840-2845.

18. Majdalawieh, A.F.; Fayyad, M.W.; Nasrallah, G.K. Anti-cancer properties and mechanisms of action of thymoquinone, the major active ingredient of Nigella sativa. Critical reviews in food science and nutrition. 2017, 57, 3911-3928.

19. Effenberger, K.; Breyer, S.; Schobert, R. Terpene conjugates of the Nigella sativa seedâ€• oil constituent thymoquinone with enhanced efficacy in cancer cells. Chemistry \& biodiversity. 2010, 7, 129-139.

20. Elmowafy, M.; Samy, A.; Raslan, M.A.; Salama, A.; Said, R.A.; Abdelaziz, A.E.; El-Eraky, W.; El Awdan, S.; Viitala, T. Enhancement of bioavailability and pharmacodynamic effects of thymoquinone via nanostructured lipid carrier (NLC) formulation. AAPS Pharm Sci Tech. 2016, 17, 663-672.

21. Moore, H.W.; Shelden, H.R. Rearrangement of azidoquinones. Reaction of thymoquinone and 2, 5-dimethyl-1, 4-benzoquinone with sodium azide in trichloroacetic acid. The Journal of Organic Chemistry. 1969, 33, 4019-4024.

22. Moore, H.W.; Shelden, H.R.; Deters, D.W.; Wikholm, R.J. Rearrangements of azidoquinones. V. Stereoselective acid-catalyzed rearrangements of azidoquinones to. gamma.-cyanoalkylidine-(cyanoarylidine-). DELTA.. alpha.,. beta.-butenolides. Journal of the American Chemical Society. 1970, 92, 1675-1681.

23. Iqbal, M.S.; Jafri, A.; Arshad, M.; Ansari, M.I. Stress response due to sodium azide treatment inside Nigella sativa L. plant and its effect on antioxidative property. 
Biocatalysis and Agricultural Biotechnology - Elsevier. 2019, 19, doi.org/10.1016/j.bcab.2019.101171

24. Iqbal, M.S.; Ansari, M.I. Biotechnological exercises in the production of secondary metabolites and its significance in health care practices. In book: Natural Bio-active Compounds Springer Nature Singapore Pvt Ltd, Singapore. 2019, 183-204, doi: 10.1007/978-981-13-7438-8_7

25. Zhao, J.; Davis, L.C.; Verpoorte, R. Elicitor signal transduction leading to production of secondary metabolites. Biotechnol Adv. 2005, 23, 283-333. doi: 10.1016/j.biotechadv.2005.01.003

26. Faiz, S.; Zahoor, A.F.; Rasool, N.; Yousaf, M.; Mansha, A.; Zia-Ul-Haq, M.; Jaafar, H.Z. Synthesis and Consecutive Reactions of $\alpha$-Azido Ketones: A Review. Molecules. 2015, 20(8), 14699-14745. doi:10.3390/molecules200814699

27. Yafizham.; Bagus, H. The effects of sodium azide on seed germination and seedling growth of chili pepper (Capsicum annum L. cv. Landung). IOP Conference Series: Earth and Environmental Science. 2018, 102(1),012052. doi:10.1088/1755-1315/102/1/012052

28. Fahad, Al-Q. Effects of sodium azide on growth and yield traits of Eruca sativa (L.). World Applied Sciences Journal. 2009, 7 (2): 220-226.

29. Sawant, R.; Godghate, A. Qualitative phytochemical screening of rhizomes of Curcuma longa L. International Journal of Science Environment and Technology. 2013, 2. 634-641.

30. Belete, Y.; Dagne, E. HPTLC assay of thymoquinone in black seed and black seed oil (Nigella Sativa Linn) and identification of thymoquinone conversion with Uv-Vis. Journal of Drug Delivery and Therapeutics. 2014, 4, 5-9.

31. Fieser, L.F.; Hartwell, J.L. The reaction of hydrazoic acid with the naphthoquinones. Journal of the American Chemical Society. 1935, 57, 1482-1484.

32. Gurung, R.L.; Lim, S.N.; Khaw, A.K.; Soon, J.F.; Shenoy, K.; Mohamed, A.S.; Jayapal, M.; Sethu, S.; Baskar, R.; Hande, M.P. Thymoquinone induces telomere shortening, DNA damage and apoptosis in human glioblastoma cells. PLoS One. 2010, 5(8), e12124. doi: 10.1371/journal.pone.0012124.

33. Babazadeh, B.; Sadeghnia, H.R.; Safarpour K.E.; Parsaee, H.; Nasri. S.; Tayarani-Najaran, Z. Protective effect of Nigella sativa and thymoquinone on serum/glucose deprivationinduced DNA damage in PC12 cells. Avicenna J Phytomed. 2012, 2(3):125-32. 
34. Parray, J.A.; Kamili, A.N.; Hamid, R.; Reshi, Z.A.; Qadri, R. A. Antibacterial and antioxidant activity of methanol extracts of Crocus sativus L.c.v. Kashmiri anus. Frontiers in Life Science. 2015, 8(1), 40-46.

35. Iqbal, M.S.; Iqbal, Z.; Ansari, M.I. Enhancement of total antioxidant and flavonoid (Quercetin) by methyl jasmonate elicitation in tissue culture of Allium cepa L. Acta Agrobotanica. 2019, 72(3):1784. doi.org/10.5586/aa.1784 PR

36. Murashige, T.; Skoog, F. A revised medium for rapid growth and bioassays with tobacco tissue cultures. Physiology plantarum. 1962, 15, 473-479.

37. Iqbal, M.S.; Ahmad, A.; Pandey, B. Solvent optimization for extraction of thymoquinone from Nigella sativa Linn. and its quantification using RP- HPLC. Physiology and molecular biology of plant. 2018, 24(6), 1209-1219. doi: 10.1007/s12298-018-0593-5.

38. Hadad, G.M.; Abdel Salam, R.A.; Soliman, R.M.; Mesbah, M.K. HPLC-DAD determination of seven antioxidants and caffeine in different phytopharmaceuticals. Journal of chromatographic science. 2013, 52, 617-623.

39. Jafri, A.; Bano, S.; Rais, J.; Khan, F.; Shivnath, N.; Sharma, A.K.; Arshad, M. Phytochemical screening of Sterculia foetida seed extract for anti-oxidant, anti-microbial activity, and detection of apoptosis through reactive oxygen species (ROS) generation, mitochondrial membrane potential (MMP) decrease, and nuclear fragmentation in human osteosarcoma cells. Journal of Histotechnology. 2019, 42, 68-79.

40. Parray, J.A.; Azra, N.; Kamili, S.J.; et al. Manipulation of Plant Growth Regulators on Phytochemical Constituents and DNA Protection Potential of the Medicinal Plant Arnebia benthamii. BioMed Research International. $\quad$ 2018, $6870139, \quad 8$. doi.org/10.1155/2018/6870139. 